\title{
Three-Dimensional Triptycene-Based Covalent Organic Frameworks with ceq or acs Topology
}

\author{
Hui Li, ${ }^{\S, \dagger}$ Fengqian Chen, ${ }^{\S, \dagger}$ Xinyu Guan, ${ }^{\dagger}$ Jiali Li, Cuiyan Li, Bin Tang, ${ }^{*},{ }^{\ddagger}$ Valentin Valtchev, $,{ }^{\perp}, \|$ Yushan \\ Yan, ${ }^{\#}$ Shilun Qiu, ${ }^{\dagger}$ and Qianrong Fang, ${ }^{* \dagger}$ \\ †State Key Laboratory of Inorganic Synthesis and Preparative Chemistry, Jilin University, Changchun 130012, P. R. China \\ Deakin University, Institute for Frontier Materials, Geelong, Victoria 3216, Australia \\ ${ }^{\perp}$ Qingdao Institute of Bioenergy and Bioprocess Technology, Chinese Academy of Sciences, 189 Songling Road, Laoshan \\ District, Qingdao, Shandong 266101, P. R. China
}

${ }$ Normandie Univ, ENSICAEN, UNICAEN, CNRS, Laboratoire Catalyse et Spectrochimie, 6 Marechal Juin, 14050

Caen, France

\#Department of Chemical and Biomolecular Engineering, Center for Catalytic Science and Technology, University of

Delaware, Newark, DE 19716, USA

Supporting Information Placeholder

\begin{abstract}
The growth of three-dimensional covalent organic frameworks (3D COFs) with new topologies is still considered as a great challenge due to limited availability of high-connectivity building units. Here we report the design and synthesis of novel 3D triptycene-based COFs, termed JUC-568 and JUC-569, following the deliberate symmetry-guided design principle. By combining a triangular prism (6-connected) node with a planar triangle (3connected) or another triangular prism node, the targeted COFs adopt unreported ceq or non-interpenetrated acs topology, respectively. Both materials show permanent porosity and impressive performance in the adsorption of $\mathrm{CO}_{2}\left(\sim 98 \mathrm{~cm}^{3} / \mathrm{g}\right.$ at $273 \mathrm{~K}$ and 1 bar), $\mathrm{CH}_{4}\left(\sim 48 \mathrm{~cm}^{3} / \mathrm{g}\right.$ at $273 \mathrm{~K}$ and 1 bar), and especially $\mathrm{H}_{2}$ (up to $274 \mathrm{~cm}^{3} / \mathrm{g}$ or $2.45 \mathrm{wt} \%$ at $77 \mathrm{~K}$ and 1 bar), which is highest among porous organic materials reported to date. This research thus provides a promising strategy for diversifying 3D COFs based on complex building blocks and promotes their potential applications in energy storage and environment-related fields.
\end{abstract}

Covalent organic frameworks (COFs), an emerging family of crystalline porous polymers, are assembled from organic reactants by reversible covalent bonds. ${ }^{1-5}$ Due to their high surface area, modular nature, and good thermal/chemical stability, COF materials have attracted considerable attention in gas storage/separation, ${ }^{6-9}$ organic electronics, ${ }^{10-14}$ heterogeneous catalysis, ${ }^{15-20}$ and some other fields. ${ }^{21-25}$ Over the past decade, most of reports were focused on conjugated two-dimensional (2D) sheets, in which the abundant building blocks allowed to establish well developed synthetic strategies. ${ }^{5}$ By contrast, three-dimensional (3D) COFs are still less studied due to the scant availability of appropriate molecular building units and relatively complex structure determination. ${ }^{4} \mathrm{Up}$ till now, only very limited topologies in $3 \mathrm{D}$ COFs have been reported, ${ }^{26-34}$ such as dia, ctn and bor. Moreover, almost all known 3D COFs were constructed by using tetrahedral (4-connected) building blocks, including the derivatives of tetraphenylmethane, tetraphenylsilane, and adamantane, which has greatly confined the structural diversity and functionalization of 3D COFs.

Despite the above issues, 3D COFs are considered as an exciting platform for practical applications due to their unique features, ${ }^{4}$ e.g., inter-connective porous structures, high specific surface areas, and easily accessible active sites. In principle, the employment of high-connectivity building units, such as triangular prism (6-connected) monomers, can set up new architectures in 3D COFs, proved by several cases that appeared recently. For example, we synthesized the first 3D large-pore COF, JUC-564, with stp topology constructed from a triptycene-based triangular prism monomer, which has the largest pore ( $43 \AA$ ) among 3D COFs and record-breaking low density $\left(0.108 \mathrm{~g} \mathrm{~cm}^{-3}\right)$ in porous crystalline materials to date. ${ }^{35}$ Subsequently, Cooper and co-workers also reported the first cage-based $3 \mathrm{D} \mathrm{COF}, 3 \mathrm{D}-\mathrm{CageCOF}-1$, which is fabricated by an organic cage molecule as a triangular prism node and adopts a 2-fold interpenetrated acs topology. ${ }^{36}$ It must be noted, however, that except for a few successful examples, 3D COFs using high-connectivity monomers still remain largely unexplored.

Herein we report the design and synthesis of new 3D COFs, termed JUC-568 and JUC-569 (JUC = Jilin University China), based on triptycene derivatives with a triangular prism node. By combining the triptycene-based monomer with a planar triangle (3connected) node, JUC-568 shows a ceq topology. Besides, from the assembly of two similar triangular prism building units, JUC-569 adopts a non-interpenetrated acs topology. To the best of our knowledge, this study represents the first example of COFs with ceq or non-interpenetrated acs topology, which effectively expands the structural varieties of 3D COFs. More importantly, owing to the high crystallinity and permanent porosity, these triptycene-based COFs demonstrate an impressive performance in the capture of $\mathrm{CO}_{2}\left(\sim 98 \mathrm{~cm}^{3} / \mathrm{g}\right.$ at $273 \mathrm{~K}$ and 1 bar $)$ and $\mathrm{CH}_{4}\left(\sim 48 \mathrm{~cm}^{3} / \mathrm{g}\right.$ at 273 $\mathrm{K}$ and 1 bar), and particularly $\mathrm{H}_{2}$ (up to $274 \mathrm{~cm}^{3} / \mathrm{g}$ at $77 \mathrm{~K}$ and 1 bar), which is higher than those from porous organic materials reported so far.

Our strategy for preparing $3 \mathrm{D}$ COFs with new topologies is based on the considered symmetry-guided design principle. A triptycene derivative, 2,3,6,7,14,15-hexa(4'-formylphenyl) triptycene (HFPTP, Figure 1b), can perfectly act as a highly 
Scheme 1. Schematic representation of the strategy for preparing 3D triptycene-based COFs ${ }^{a}$

a)

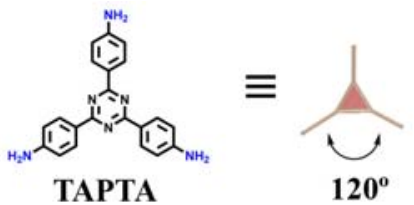

$+$

b)

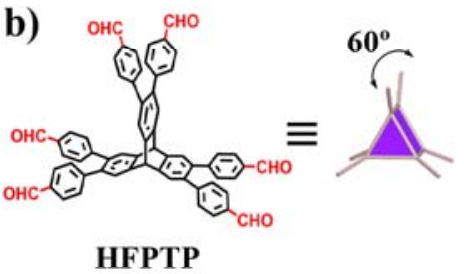

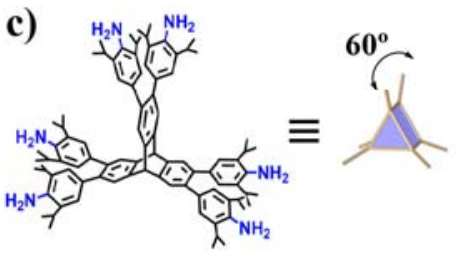

HDIATP d)

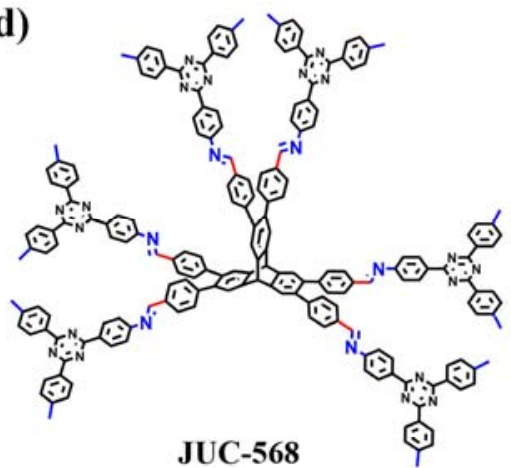

e)

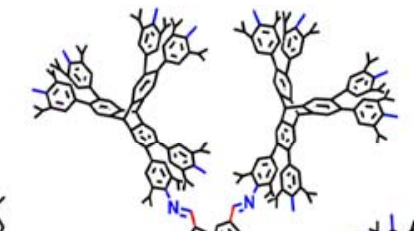

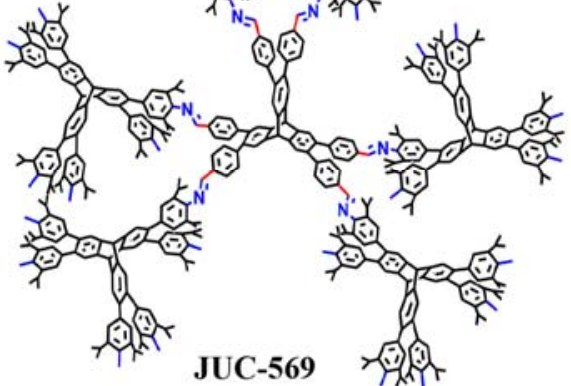

f)

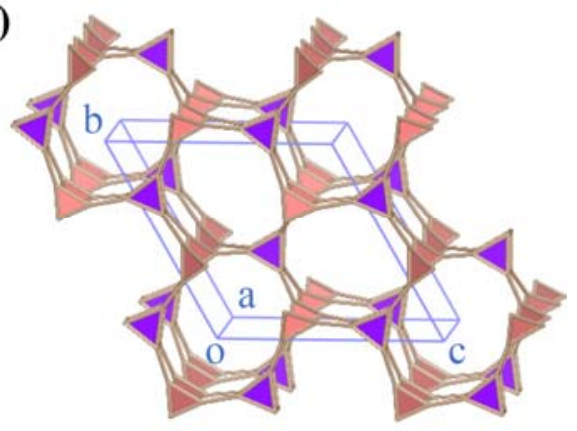

ceq net

g)

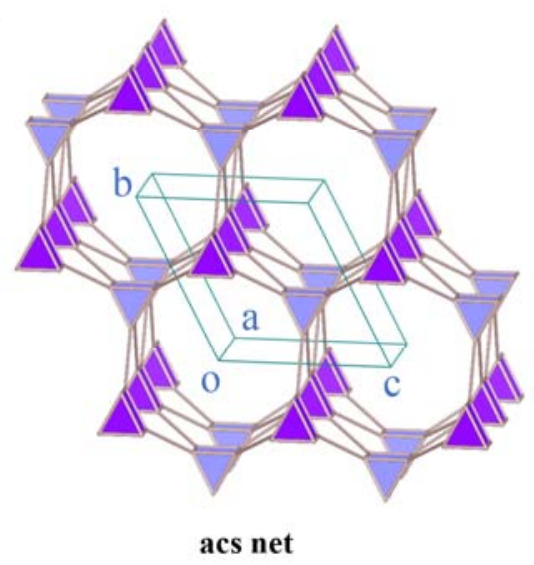

${ }^{a}$ Molecular structures of TAPTA (a) as a planar triangle (3-connected) node as well as HFPTP (b) and HDIATP (c) as triangular prism nodes (6-connected) building units. Two 3D triptycene-based COFs, denoted as JUC-568 (d) and JUC-569 (e), are constructed by the condensation reaction of HFPTP and TAPTA or HDIATP. An expanded [6+3] connected network (ceq topology) in JUC-568 (f), and an expanded $[6+6]$ connected network (acs topology) in JUC-569 (g).

symmetrical triangular prism node. After analyzing the Reticular Chemistry Structure Resource (RCSR) database, ${ }^{37}$ we found that only one possible topology (acs) is available for such a 6-connected node. At the same time, there are multiple feasible topologies for the combination of 6-connected and 3-connected build units, such as ceq, sab and dag. Therefore, the condensation of HFPTP and a planar triangle (3-connected) monomer, 2,4,6-tris(4-aminophenyl)1,3,5-triazine (TAPTA, Figure 1a), leads to an expanded [6+3] connected network (JUC-568, Figure 1d). Considering their link angles $\left(60^{\circ}\right.$ for HFPTP and $120^{\circ}$ for TAPTA), the targeted material is more likely to form the ceq topology (Figure 1f). Furthermore, to construct a pure 6-connected framework, another triangular prism monomer, 2,3,6,7,14,15-hexa(3',5'-diisopropyl-4'-amino) triptycene (HDIATP, Figure 1c) was also designed. JUC-569 (Figure 1e) can be obtained from the combination of two triangular prism monomers, HFPTP and HDIATP, with the same 6-connected node and link angle of $120^{\circ}$, which tends to a non-interpenetrated acs topology (Figure 1g).

The synthesis of JUC-568 was carried out by the solvothermal reaction of HFPTP $(22.0 \mathrm{mg}, 0.025 \mathrm{mmol})$ and TAPTA $(17.7 \mathrm{mg}$, $0.05 \mathrm{mmol}$ ) in a mixture of dioxane, mesitylene and acetic acid, with heating at $120^{\circ} \mathrm{C}$ for 3 days; while JUC- 569 was obtained by suspending HFPTP (22.0 mg, $0.025 \mathrm{mmol})$ and HDIATP $(32.3 \mathrm{mg}$, $0.025 \mathrm{mmol})$ in a mixture of $o$-dichlorobenzene, $n$-butanol and acetic acid under $120^{\circ} \mathrm{C}$ for 3 days. The as-synthesized COFs were insoluble in water or common organic solvents, such as hexane, a)

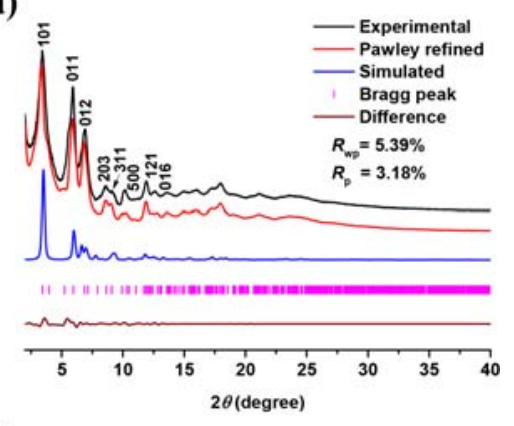

b)

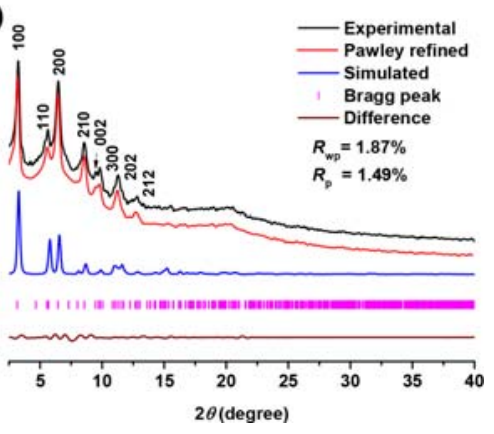

Figure 1. PXRD patterns of JUC-568 (a) and JUC-569 (b). 
acetone, $N, N$-dimethylformamide, ethanol, and tetrahydrofuran. The morphologies of both COFs were characterized by scanning electron microscopy (SEM, Figures S1 and S2). Fourier transform infrared (FT-IR) spectra displayed new peaks at $1598 \mathrm{~cm}^{-1}$ for JUC-568 and $1625 \mathrm{~cm}^{-1}$ for JUC-569, which are typical characteristics of $\mathrm{C}=\mathrm{N}$ bond. At the same time, the depletion of peaks ascribed to $\mathrm{C}=\mathrm{O}$ stretching vibration $\left(1699 \mathrm{~cm}^{-1}\right.$ for HFPTP) and N-H stretching vibration $\left(\sim 3323 \mathrm{~cm}^{-1}\right.$ for TAPTA and $\sim 3403$ $\mathrm{cm}^{-1}$ for HDIATP) confirmed that aldehyde and amine groups had been transformed (Figures S3 and S4). Solid-state ${ }^{13} \mathrm{C}$ crosspolarization magic-angle-spinning (CP/MAS) NMR spectroscopy indicated that the presence of carbons from imine groups by the peaks at 158 ppm for JUC-568 and 162 ppm for JUC-569 (Figures S5 and S6). Thermogravimetric analysis (TGA) showed that both COFs had high thermal stability $\left(\sim 450^{\circ} \mathrm{C}\right.$, Figures S7 and S8).
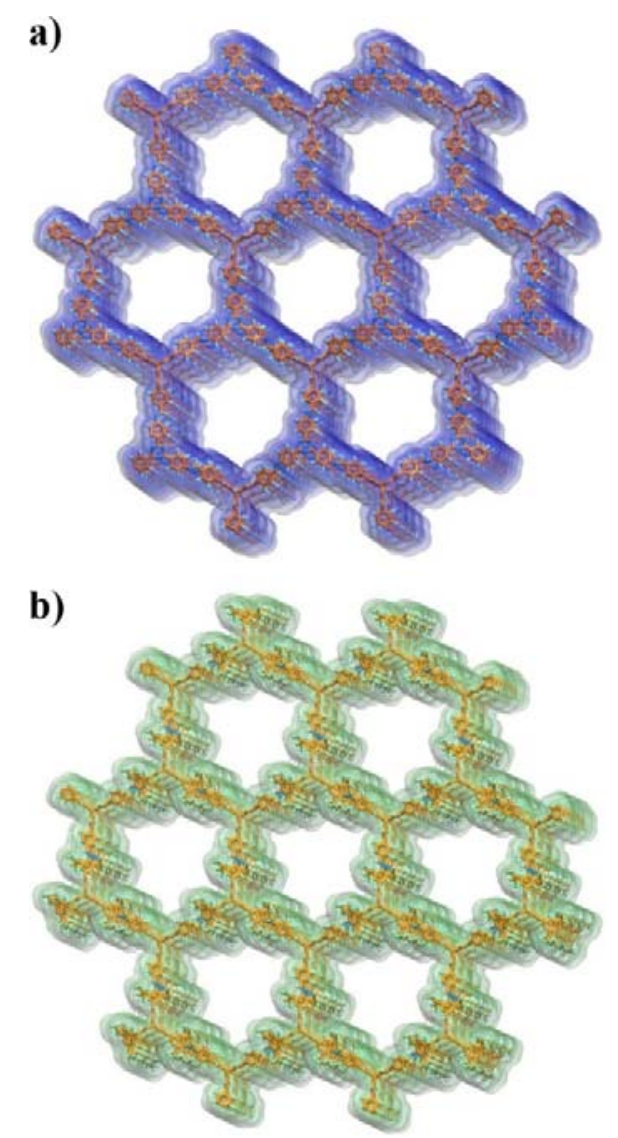

Figure 2. Extended structures of JUC-568 (a) and JUC-569 (b) viewed along $c$-axis.

The crystalline structures of 3D triptycene-based COFs were verified by the powder X-ray diffraction (PXRD) in conjunction with structural simulations (Figure 1). After a geometrical energy minimization by the Materials Studio software package, ${ }^{38}$ the unit cell parameters were acquired with $a=49.570 \AA, b=50.541 \AA, c$ $=15.618 \AA$ and $\alpha=\beta=90^{\circ}, \gamma=120^{\circ}$ for JUC-568 based on a ceq net, while the unit cell parameters of JUC-569 with a noninterpenetrated acs net were $a=b=31.110 \AA, c=18.468 \AA$ and $\alpha$ $=\beta=90^{\circ}, \gamma=120^{\circ}$. Moreover, the experimental PXRD patterns were accomplished by full profile pattern matching (Pawley) refinement. Peaks at 3.43, 5.92, 6.82, 8.65, 9.08, 10.21,11.86 and $12.70^{\circ}$ for JUC-568 belong to the (101), (011), (012), (203), (311), (500), (121) and (016) Bragg peaks of the space group Pm (No. 6), and peaks at $3.24,5.61,6.47,8.55,9.48,9.87,11.30$ and $12.84^{\circ}$ for
JUC-569 correspond to the (100), (110), (200), (210), (002), (300), (202) and (212) Bragg peaks of the space group P-6 (No. 174). The calculated results can well match those experimental ones with good agreement factors $(R \mathrm{p}=3.18 \%$ and $\omega R \mathrm{p}=5.39 \%$ for JUC$568 ; R \mathrm{p}=1.49 \%$ and $\omega R \mathrm{p}=1.87 \%$ for JUC-569). In addition, we also tried alternative structures with different topologies, such as sab and dag net for JUC-568; however, there was a significant difference between the experimental and simulated PXRDs (Figures S9-11). In consideration of all these results, the obtained COFs were proposed to have the expected networks, ceq topology for JUC-568 and acs topology for JUC-569. Both COF materials show microporous cavities with $\sim 1.98 \mathrm{~nm}$ for JUC-568 and $\sim 1.94$ $\mathrm{nm}$ for JUC-569 viewed along the $c$-axis (Figure 2).
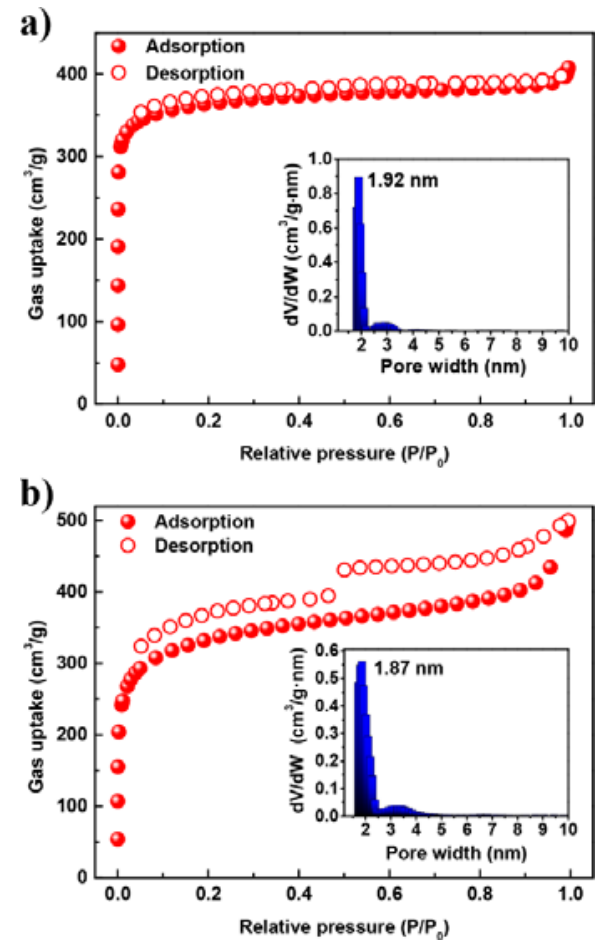

Figure 3. $\mathrm{N}_{2}$ adsorption-desorption isotherms for JUC-568 (a) and JUC-569 (b) at $77 \mathrm{~K}$. Inserts: corresponding calculated pore-size distribution.

The permanent porosity and specific surface areas of 3D triptycene-based COFs were determined by $\mathrm{N}_{2}$ adsorption measurements at $77 \mathrm{~K}$. As can be seen in Figure 3, both COFs showed a sharp increase at low pressure (below $0.1 \mathrm{P} / \mathrm{P}_{0}$ ), which reveals their microporous nature. The presence of textural mesopores in JUC-569 led to the isotherm inclination in the 0.8-1.0 $\mathrm{P} / \mathrm{P}_{0}$ range. Slight desorption hysteresis was observed, which is a consequence of the agglomeration of COF crystals. ${ }^{39}$ The Brunauer-Emmett-Teller (BET) specific surface areas were 1433 $\mathrm{m}^{2} / \mathrm{g}$ for JUC-568 and $1254 \mathrm{~m}^{2} / \mathrm{g}$ for JUC-569, respectively (Figures S9-12). The non-local density functional theory (NLDFT) was used to calculate the pore-size distribution, and both COFs showed microporous cavities with $\sim 1.92 \mathrm{~nm}$ for JUC-568 and $1.87 \mathrm{~nm}$ for JUC-569 (inserts in Figure 3), which are in good agreement with the pore sizes predicted from their crystal structures $(\sim 1.98 \mathrm{~nm}$ for JUC-568 and $\sim 1.94 \mathrm{~nm}$ for JUC-569).

Furthermore, the uptakes of $\mathrm{H}_{2}, \mathrm{CH}_{4}$ and $\mathrm{CO}_{2}$ under one atmosphere were studied to expand the potential of 3D triptycenebased COFs in the greenhouse gas capture and energy storage. As 
shown in Figure 4, JUC-568 had higher adsorption capacity of $\mathrm{CO}_{2}$ $\left(98 \mathrm{~cm}^{3} / \mathrm{g}\right.$ at $273 \mathrm{~K}$ and $81 \mathrm{~cm}^{3} / \mathrm{g}$ at $\left.298 \mathrm{~K}\right), \mathrm{CH}_{4}\left(48 \mathrm{~cm}^{3} / \mathrm{g}\right.$ at 273 $\mathrm{K}$ and $32 \mathrm{~cm}^{3} / \mathrm{g}$ at $\left.298 \mathrm{~K}\right)$ and $\mathrm{H}_{2}\left(274 \mathrm{~cm}^{3} / \mathrm{g}\right.$ at $\left.77 \mathrm{~K}\right)$ than JUC$569\left(\mathrm{CO}_{2}: 47 \mathrm{~cm}^{3} / \mathrm{g}\right.$ at $273 \mathrm{~K}$ and $31 \mathrm{~cm}^{3} / \mathrm{g}$ at $298 \mathrm{~K}, \mathrm{CH}_{4}: 19 \mathrm{~cm}^{3} / \mathrm{g}$ at $273 \mathrm{~K}$ and $11 \mathrm{~cm}^{3} / \mathrm{g}$ at $298 \mathrm{~K}$, and $\mathrm{H}_{2}: 167 \mathrm{~cm}^{3} / \mathrm{g}$ at $\left.77 \mathrm{~K}\right)$. Remarkably, the $\mathrm{H}_{2}$ storage capacity $\left(274 \mathrm{~cm}^{3} / \mathrm{g}\right.$ or $\left.2.45 \mathrm{wt} \%\right)$ of JUC568 at 1 bar and $77 \mathrm{~K}$ is superior to those of porous organic materials (POMs) reported to date (Table $\mathrm{S} 1)$, such as PPN-3 (1.58 wt $\%),{ }^{40}$ PAF-1 (1.66 wt $\left.\%\right),{ }^{41}$ SPT-CMP1 $(1.72 \mathrm{wt} \%),{ }^{42}$ and DLCOF-1 (2.09 wt $\%),{ }^{43}$ which can be attributed to the unique shape of triptycene as a rigid, fused-ring skeleton and three-fold symmetry building unit. ${ }^{44}$
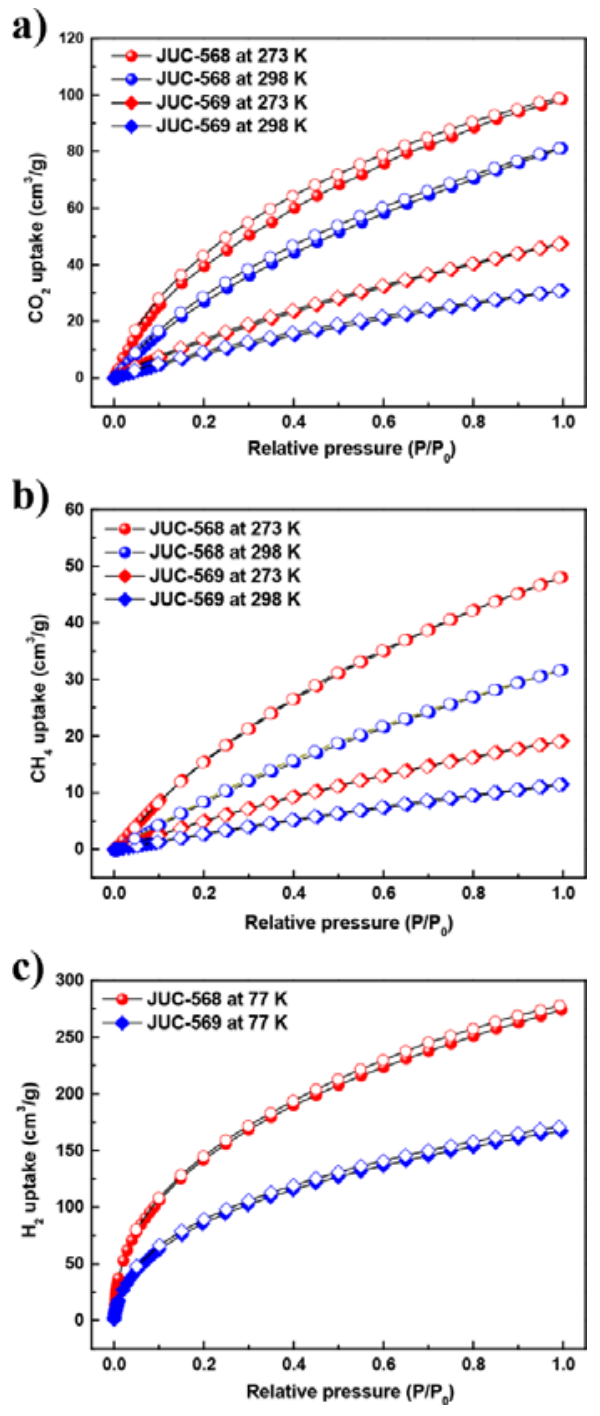

Figure 4. The uptakes of $\mathrm{CO}_{2}$ (a), $\mathrm{CH}_{4}$ (b) and $\mathrm{H}_{2}$ (c) for JUC-568 and JUC-569 measured at different temperatures.

In summary, we have developed two 3D triptycene-based COFs, JUC-568 and JUC-569, with unreported ceq or non-interpenetrated acs topology, respectively. Remarkably, JUC-568 possesses a permanent porosity and impressive performance in the uptakes of $\mathrm{CO}_{2}$ $\left(98 \mathrm{~cm}^{3} / \mathrm{g}\right.$ at $273 \mathrm{~K}$ and $\left.1 \mathrm{bar}\right)$ and $\mathrm{CH}_{4}\left(48 \mathrm{~cm}^{3} / \mathrm{g}\right.$ at $273 \mathrm{~K}$ and 1 bar), and more importantly $\mathrm{H}_{2}\left(274 \mathrm{~cm}^{3} / \mathrm{g}\right.$ or $2.45 \mathrm{wt} \%$ at $77 \mathrm{~K}$ and $1 \mathrm{bar}$ ), which is highest among porous organic materials reported so far. Thus, this work offers a new strategy for constructing 3D
COFs from high-connectivity building blocks and facilitates their future applications in energy storage and environment protection.

\section{Supporting Information}

Methods and synthetic procedures, SEM, FTIR, solid state ${ }^{13} \mathrm{C}$ NMR, TGA, BET plot, and unit cell parameters. This material is available free of charge via the internet at http://pubs.acs.org.

\section{AUTHOR INFORMATION}

\section{Corresponding Author}

*qrfang@jlu.edu.cn or bin.tang@deakin.edu.au

\section{Author Contributions}

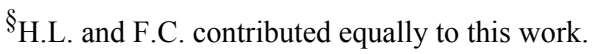

Notes

The authors declare no competing financial interests.

\section{ACKNOWLEDGMENT}

This work was supported by the National Natural Science Foundation of China (22025504, 21621001, and 21390394), "111" project (BP0719036 and B17020), and the program for JLU Science and Technology Innovative Research Team. V.V., Q.F. and S.Q. acknowledge the collaboration in the framework of China-French joint laboratory "Zeolites".

\section{REFERENCES}

(1) Côté, A. P.; Benin, A. I.; Ockwig, N. W.; O'Keeffe, M.; Matzger, A. J.; Yaghi, O. M. Porous, Crystalline, Covalent Organic Frameworks. Science 2005, 310, 1166.

(2) Colson, J. W.; Woll, A. R.; Mukherjee, A. Levendorf, M. P.; Spitler, E. L.; Shields, V. B.; Spencer, M. G.; Park, J.; Dichtel, W. R. Science 2011, 332, 228

(3) Ding, S. Y.; Wang, W. Covalent Organic Frameworks (COFs): from Design to Applications. Chem. Soc. Rev. 2013, 42, 548.

(4) Guan, X. Y.; Chen, F. Q.; Fang, Q. R.; Qiu, S. L. Design and Applications of Three Dimensional Covalent Organic Frameworks. Chem. Soc. Rev. 2020, 49, 1357.

(5) Geng, K. Y.; He, T.; Liu, R. Y.; Dalapati, S.; Tan, K. T.; Li, Z. P.; Tao, S. S.; Gong, Y. F.; Jiang, Q. H.; Jiang, D. L. Covalent Organic Frameworks: Design, Synthesis, and Functions. Chem. Rev. 2020, 120, 8814.

(6) Han, S. S.; Furukawa, H.; Yaghi, O. M.; Goddard, W. A., III Covalent Organic Frameworks as Exceptional Hydrogen Storage Materials. J. Am. Chem. Soc. 2008, 130, 11580.

(7) Kuhn, P.; Antonietti, M.; Thomas, A. Porous, Covalent TriazineBased Frameworks Prepared by Ionothermal Synthesis. Angew. Chem. Int. Ed. 2008, 47, 3450.

(8) Fang, Q. R.; Zhuang, Z. B.; Gu, S.; Kaspar, R. B.; Zheng, J.; Wang, J. H.; Qiu, S. L.; Yan, Y. S. Designed Synthesis of LargePore Crystalline Polyimide Covalent Organic Frameworks. Nat. Commun. 2014, 5, 4503.

(9) Wang, S.; Wang, Q.; Shao, P.; Han, Y.; Gao, X.; Ma, L.; Yuan, S.; Ma, X.; Zhou, J.; Feng, X.; Wang, B. Exfoliation of Covalent Organic Frameworks into Few-layer Redox-Active Nanosheets as Cathode Materials for Lithium-Ion Batteries. J. Am. Chem. Soc. 2017, 139, 4258.

(10) Wan, S.; Guo, J.; Kim, J.; Ihee, H.; Jiang, D. A Belt-Shaped, Blue Luminescent, and Semiconducting Covalent Organic Framework. Angew. Chem. Int. Ed. 2008, 47, 8826.

(11) Bertrand, G. H. V.; Michaelis, V. K.; Ong, T. C.; Griffin, R. G.; Dinca, M. Thiophene-Based Covalent Organic Frameworks. Proc. Natl. Acad. Sci. U. S. A. 2013, 110, 4923. 
(12) Dogru, M.; Handloser, M.; Auras, F.; Kunz, T.; Medina, D.; Hartschuh, A.; Knochel, P.; Bein, T. A Photoconductive Thienothiophene-Based Covalent Organic Framework Showing Charge Transfer Towards Included Fullerene. Angew. Chem. Int. Ed. 2013, 52, 2920.

(13) Du, Y.; Yang, H.; Whiteley, J. M.; Wan, S.; Jin, Y.; Lee, S. H.; Zhang, W. Ionic Covalent Organic Frameworks with Spiroborate Linkage. Angew. Chem. Int. Ed. 2016, 55, 1737.

(14) Li, H.; Chang, J. H.; Li, S. S.; Guan, X. Y.; Li, D. H.; Li, C. Y.; Tang, L. X.; Xue, M.; Yan, Y. S.; Valtchev, V.; Qiu, S. L.; Fang, Q. R. Three-Dimensional Tetrathiafulvalene-Based Covalent Organic Frameworks for Tunable Electrical Conductivity. J. Am. Chem. Soc. 2019, 141, 13324.

(15) Ding, S. Y.; Gao, J.; Wang, Q.; Zhang, Y.; Song, W. G.; Su, C. Y.; Wang, W. Construction of Covalent Organic Framework for Catalysis: Pd/COF-LZU1 in Suzuki-Miyaura Coupling Reaction. $J$. Am. Chem. Soc. 2011, 133, 19816.

(16) Vyas, V. S.; Haase, F.; Stegbauer, L.; Savasci, G.; Podjaski, F.; Ochsenfeld, C.; Lotsch, B. V. A Tunable Azine Covalent Organic Framework Platform for Visible Light-Induced Hydrogen Generation. Nat. Commun. 2015, 6, 8508.

(17) Sun, Q.; Aguila, B.; Perman, J.; Nguyen, N.; Ma, S. Q. Flexibility Matters: Cooperative Active Sites in Covalent Organic Framework and Threaded Ionic Polymer. J. Am. Chem. Soc. 2016, 138,15790

(18) Wang, X.; Han, X.; Zhang, J.; Wu, X.; Liu, Y.; Cui, Y. Homochiral 2D Porous Covalent Organic Frameworks for Heterogeneous Asymmetric Catalysis. J. Am. Chem. Soc. 2016, 138,12332 .

(19) Yan, S. C.; Guan, X. Y.; Li, H.; Li, D. H.; Xue, M.; Yan, Y. S.; Valtchev, V.; Qiu, S. L.; Fang, Q. R. Three-dimensional Salphen-based Covalent-Organic Frameworks as Catalytic Antioxidants. J. Am. Chem. Soc. 2019, 141, 2920.

(20) Bi, S.; Thiruvengadam, P.; Wei, S.; Zhang, W. B.; Zhang, F.; Gao, L. S.; Xu, J. S.; Wu, D. Q.; Chen, J. S.; Zhang, F. VinyleneBridged Two-Dimensional Covalent Organic Frameworks via Knoevenagel Condensation of Tricyanomesitylene. J. Am. Chem. Soc. 2020, 142, 11893

(21) Chandra, S.; Kundu, T.; Kandambeth, S.; BabaRao, R.; Marathe, M. Y.; Kunjir, S. M.; Banerjee, R. Phosphoric Acid Loaded Azo $(-\mathrm{N}=\mathrm{N}-)$ Based Covalent Organic Framework for Proton Conduction. J. Am. Chem. Soc. 2014, 136, 6570.

(22) Zhou, T. Y.; Xu, S. Q.; Wen, Q.; Pang, Z. F.; Zhao, X. OneStep Construction of Two Different Kinds of Pores in a 2D Covalent Organic Framework. J. Am. Chem. Soc. 2014, 136, 15885.

(23) Guan, X. Y.; Li, H.; Ma, Y. C.; Xue, M.; Fang, Q. R.; Yan, Y. S.; Valtchev, V.; Qiu, S. L. Chemically Stable PolyaryletherBased Covalent Organic Frameworks. Nat. Chem. 2019, 11, 587.

(24) Guo, Z. B.; Zhang, Y. Y.; Dong, Y.; Li, J.; Li, S. W.; Shao, P. P.; Feng, X.; Wang, B. Fast Ion Transport Pathway Provided by Polyethylene Glycol Confined in Covalent Organic Frameworks. $J$. Am. Chem. Soc. 2019, 141, 1923.

(25) Li, D. H.; Li, C. Y.; Zhang, L. J.; Li, H.; Zhu, L. K.; Yang, D. J.; Fang, Q. R.; Qiu, S. L.; Yao, X. D. Metal-Free ThiopheneSulfur Covalent Organic Frameworks: Precise and Controllable Synthesis of Catalytic Active Sites for Oxygen Reduction. J. Am. Chem. Soc. 2020, 142, 8104.

(26) El-Kaderi, H. M.; Hunt, J. R.; Mendoza-Cortes, J. L.; Côté, A. P.; Taylor, R. E.; O'Keeffe, M.; Yaghi, O. M. Designed Synthesis of 3D Covalent Organic Frameworks. Science 2007, 316, 268.

(27) Fernando, J.; Uribe-Romo, J. R. H.; Furukawa, H.; Klo, C.; O'Keeffe M.; Yaghi, O. M. A Crystalline Imine-Linked 3-D Porous Covalent Organic Framework. J. Am. Chem. Soc. 2009, 131, 4570.
(28) Ma, T.; Kapustin E. A.; Yin, S. X.; Liang, L.; Zhou, Z.; Niu, J.; Li, L. H.; Wang, Y.; Su, J.; Li, J.; Wang, X.; Wang, W. D.; Wang, W.; Sun, J.; Yaghi, O. M. Single-Crystal X-ray Diffraction Structures of Covalent Organic Frameworks. Science 2018, 361, 48.

(29) Lin, G.; Ding, H.; Yuan, D.; Wang, B.; Wang, C. A PyreneBased, Fluorescent Three-Dimensional Covalent Organic Framework. J. Am. Chem. Soc. 2016, 138, 3302.

(30) Zhang, Y.; Duan, J.; Ma, D.; Li, P.; Li, S.; Li, H.; Zhou, J.; Ma, X.; Feng, X.; Wang, B. Three-Dimensional Anionic CyclodextrinBased Covalent Organic Frameworks. Angew. Chem. Int. Ed. 2017, 56, 16313

(31) Yahiaoui, O.; Fitch, A. N.; Hoffmann, F.; Froba, M.; Thomas, A.; Roeser, J. 3D Anionic Silicate Covalent Organic Framework with srs Topology. J. Am. Chem. Soc. 2018, 140, 5330.

(32) Lan, Y.; Han, X.; Tong, M.; Huang, H.; Yang, Q.; Liu, D.; Zhao, X.; Zhong, C. Materials Genomics Methods for HighThroughput Construction of COFs and Targeted Synthesis. Nat. Commun. 2018, 9, 5274

(33) Kang, X.; Han, X.; Yuan, C.; Cheng, C.; Liu, Y.; Cui, Y. Reticular Synthesis of tbo Topology Covalent Organic Frameworks. J. Am. Chem. Soc. 2020, 142, 16346.

(34) Gropp, C.; Ma, T. Q.; Hanikel, N.; Yaghi, O. M. Design of Higher Valency in Covalent Organic Frameworks. Science 2020, $370,6406$.

(35) Li, H.; Ding, J. H.; Guan, X. Y.; Chen, F. Q.; Li, C. Y.; Zhu, L. K.; Xue, M.; Yuan, D. Q.; Valtchev, V.; Yan, Y. S.; Qiu, S. L.; Fang, Q. R. Three-Dimensional Large-Pore Covalent Organic Framework with stp Topology. J. Am. Chem. Soc. 2020, 142, 13334.

(36) Zhu, Q.; Wang, X.; Clowes, R.; Cui, P.; Chen, L. J.; Little, M. A.; Cooper, A. I. 3D Cage COFs: A Dynamic Three-Dimensional Covalent Organic Framework with High-Connectivity Organic Cage Nodes. J. Am. Chem. Soc. 2020, 142, 16842.

(37) http://rcsr.net/nets.

(38) Materials Studio ver. 7.0; Accelrys Inc.: San Diego, CA.

(39) Fang, Q.; Wang, J.; Gu, S.; Kaspar, R. B.; Zhuang, Z.; Zheng, J.; Guo, H.; Qiu, S.; Yan, Y. 3D Porous Crystalline Polyimide Covalent Organic Frameworks for Drug Delivery. J. Am. Chem. Soc. 2015, 137, 8352.

(40) Lu, W.; Yuan, D.; Zhao, D.; Schilling, C. I.; Plietzsch, O.; Muller, T.; Brase, S.; Guenther, J.; Blümel, J.; Krishna, R.; Li, Z.; Zhou, H. C. Porous Polymer Networks: Synthesis, Porosity, and Applications in Gas Storage/Separation. Chem. Mater. 2010, 22, 5964.

(41) Ben, T.; Ren, H.; Ma, S.; Cao, D.; Lan, J.; Jing, X.; Wang, W.; Xu, J.; Deng, F.; Simmons, J. M.; Qiu, S. L.; Zhu, G. S. Targeted Synthesis of a Porous Aromatic Framework with High Stability and Exceptionally High Surface Area. Angew. Chem. Int. Ed. 2009, 48, 9457.

(42) Jiang, J. X.; Laybourn, A.; Clowes, R.; Khimyak, Y. Z.; Bacsa, J.; Higgins, S. J.; Adams D. J.; Cooper, A. I. High Surface Area Contorted Conjugated Microporous Polymers Based on Spiro-Bipropylenedioxythiophene. Macromolecules 2010, 43, 7577.

(43) Li, H.; Pan, Q. Y.; Ma, Y. C.; Guan, X. Y.; Xue, M.; Fang, Q. R.; Yan, Y. S.; Valtchev, V.; Qiu, S. L. Three-Dimensional Covalent Organic Frameworks with Dual Linkages for Bifunctional Cascade Catalysis. J. Am. Chem. Soc. 2016, 138, 14783.

(44) Ghanem, B. S.; Msayid, K. J.; Mckeown, N. B.; Harris, K. D.; Pan, Z. G.; Budd, P. M.; Butler, A.; Selbie, J.; Book, D.; Walton, A. A Triptycene-Based Polymer of Intrinsic Microposity That Displays Enhanced Surface Area and Hydrogen Adsorption. Chem. Commun. 2007, 1, 67. 
TOC Graphic:

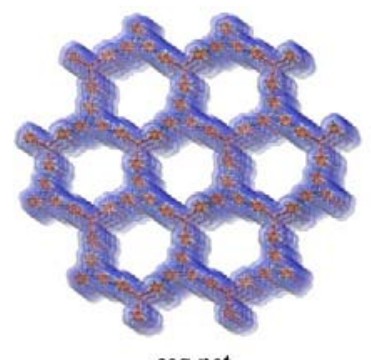

ceq net

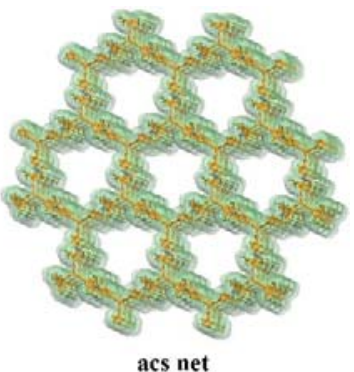

acs net 